\title{
ASTAR Flight Test: Overview and Spacing Results
}

\author{
Roy D. Roper ${ }^{1}$ and Michael R. Koch ${ }^{2}$ \\ National Aeronautics and Space Administration, Langley Research Center, Hampton, VA 23681
}

The purpose of the NASA Langley Airborne Spacing for Terminal Arrival Routes (ASTAR) research aboard the Boeing ecoDemonstrator aircraft was to demonstrate the use of NASA's ASTAR algorithm using contemporary tools of the Federal Aviation Administration's Next Generation Air Transportation System (NEXTGEN). EcoDemonstrator is a Boeing test program which utilizes advanced experimental equipment to accelerate the science of aerospace and environmentally friendly technologies. The ASTAR Flight Test provided a proof-of-concept flight demonstration that exercised an algorithmic-based application in an actual aircraft. The test aircraft conducted Interval Management operations to provide time-based spacing off a target aircraft in non-simulator wind conditions. Work was conducted as a joint effort between NASA and Boeing to integrate ASTAR in a Boeing supplied B787 test aircraft while using a T-38 aircraft as the target. This demonstration was also used to identify operational risks to future flight trials for the NASA Air Traffic Management Technology Demonstration expected in 2017.

\section{Nomenclature}

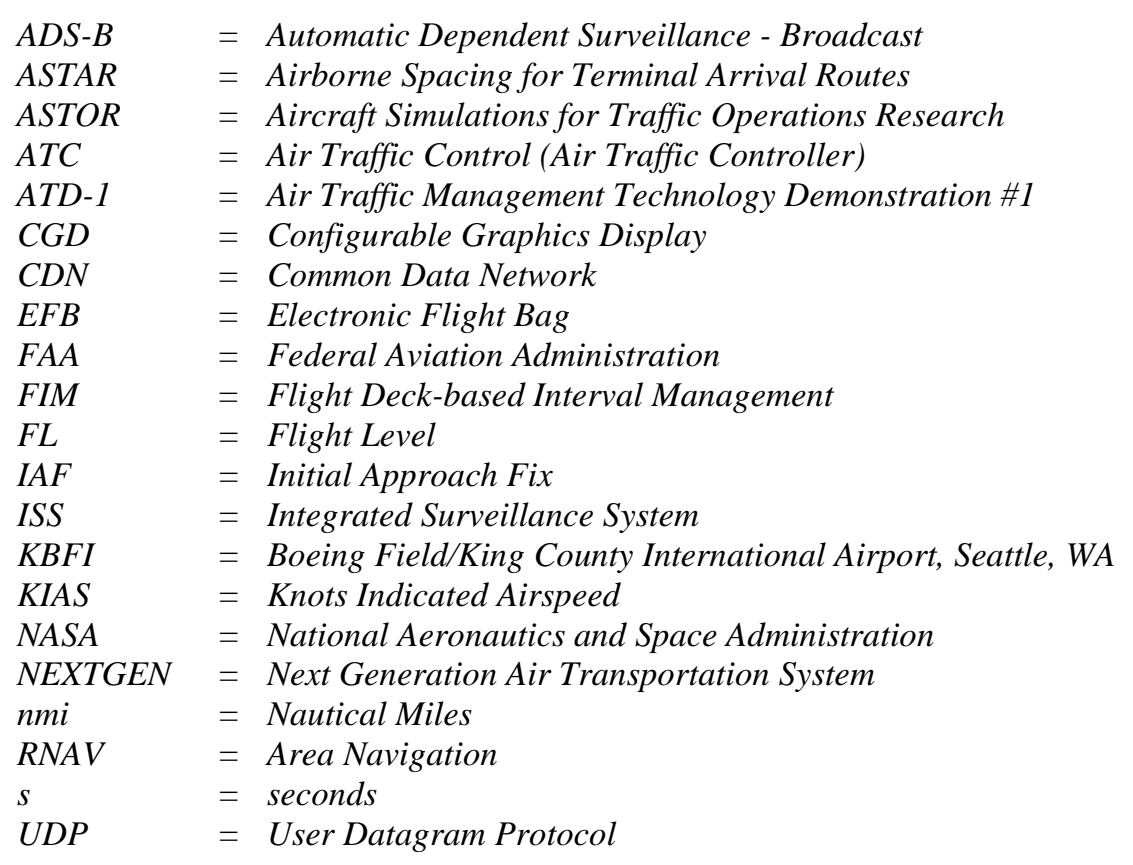

\section{Introduction}

$\mathrm{T}$ he Air Traffic Management Technology Demonstration-1 (ATD-1) is a major applied research and development activity of NASA's Airspace Operations and Safety Program. The demonstration is the first of a series of Air

\footnotetext{
${ }^{1}$ Research Aerospace Engineer, NASA Langley Research Center, 24 W. Taylor St., MS 152, Hampton, VA 236812199.

2 Electronics/Avionics Engineer, NASA Langley Research Center, 24 W. Taylor St. MS 152, Hampton, VA 236812199.
} 
Traffic Management sub-projects that demonstrate innovative NASA technologies that have attained a sufficient level of maturity to merit more in-depth evaluation and development at the system level in relevant environments. A primary goal of ATD-1 is to operationally demonstrate an integrated set of NASA arrival management technologies for planning and executing efficient arrival operations in the terminal environment of a high-density airport. These technologies are: advanced Traffic Management Advisor - Terminal Metering (for planning), flight deck interval management (for airborne spacing), and controller-managed spacing (for ground-based spacing). FAA projections envision airborne spacing pre-implementation starting in 2017 with operational availability in the National Airspace System by $2020^{1}$.

To address the airborne technology component, researchers at NASA Langley Research Center developed a trajectory-based control law for time-based spacing for Flight deck Interval Management (FIM) operations. The algorithm, Airborne Spacing for Terminal Arrival Routes ver. 12 (ASTAR-12), builds a 4-D trajectory flight path for both a target aircraft and the ownship based on the clearance assigned to each. It then employs Automatic Dependent Surveillance - Broadcast (ADS-B) In messaging and onboard sensors to determine current position along the respective trajectories and calculates an estimated time of arrival for each aircraft to cross a common point (known as the Achieve-By Point). The difference between the estimated time of arrival (e.g., 97 s), minus the desired time spacing goal (e.g., $90 \mathrm{~s}$ ), is the spacing error (e.g., 7 s) the algorithm attempts to drive to zero with speed guidance $^{2}$. The desired spacing goal is required to be met no later than when the trailing aircraft crosses the Achieve-By Point, which helps to keep speed guidance close to constraints found in published procedures. As the speed guidance is executed by the flight crews, the aircraft conforms to very precise spacing intervals and procedures, thus simultaneously enabling increased airport arrival capacity and more efficient aircraft operations ${ }^{3,4,5}$.

Although the success of ATD-1 is only fully realized by the integrated execution of all three stated technologies, an interim activity demonstrating just the flight deck automation could facilitate avionics development and assist in the planning of future ATD-1 flight trials. In April 2013, such an opportunity presented itself when NASA and Boeing were searching for emerging aviation technologies that could be rapidly integrated with and demonstrated on Boeing's ecoDemonstrator ${ }^{6}$ test aircraft. Each year or so, Boeing designates an asset to function as a flight test bed, which serves two purposes. First, it serves as schedule risk mitigation by accelerating the technical readiness of prototype systems. This is accomplished by providing a means to conduct flight tests on systems outside of the certification process and allows for a concentration of testing. Secondly, it opens the door for Boeing to collaborate with vendors and research facilities to test new concepts in a relative flight environment. Researchers gain access to affordable flight test time, and Boeing can evaluate new technologies sooner than it otherwise could.

Candidate technologies for the proposed collaboration were required to be sufficiently mature, have relatively few integration requirements, and promise benefit to the aviation community. It was soon determined that the enabling technology behind the airborne component of the ATD-1 suite of tools was a good fit and was selected for the demonstration, which was subsequently named the ASTAR Flight Test .

The primary objective of the ASTAR Flight Test was to identify operational risks for future ATD-1 flight tests. Secondly, the ASTAR Flight Test would exercise in-flight use of the ASTAR algorithm's calculated speed command on a modern transport category aircraft to show the potential for safe and manageable spacing operations in the National Airspace System. Data collected was used to validate some ATD-1 FIM system requirements and investigate FIM operations prior to release of the Airborne Spacing FIM Minimum Operational Performance Standards ${ }^{7}$. A final objective was to demonstrate a collaborative rapid prototype effort with an industry partner. Success relied on the ability of NASA and Boeing to rapidly port an ASTAR-based application to a laptop computer, integrate it on the ecoDemonstrator test aircraft, and be ready to conduct flight tests by the fall of 2014 .

The ASTAR Flight Test was conducted as a collaborative effort between NASA and Boeing. Boeing contributed flight test time on the company’s 2013 ecoDemonstrator aircraft (B787-800), and NASA developed a prototype system to host a cockpit based spacing tool used to facilitate more efficient arrival operations. In addition, NASA and Boeing collaborated to integrate the FIM avionics into the aircraft and staff flight operations.

\section{Implementation}

Development occurred across multiple stages for a highly collaborative effort between NASA Langey Research Center, Boeing, the Seattle air traffic control authority, and Grant County Approach controllers. Implementation required software architecture modifications to include a communications bridge between computing languages, development testing at multiple locations, and integration testing within the Boeing Avionics Integration Lab and the ecoDemonstrator aircraft. Flight test plan development and training occurred in parallel, leading up to a functional test flight and flight demonstration. 


\section{A. Architecture}

The B787 avionics was developed with an open architecture platform philosophy enabling the adoption of new applications with relative ease. The primary communication vehicle was the Common Data Network (CDN). The CDN designed systems have common Ethernet ports allowing direct connection between the flight test laptop and the ecoDemonstrator flight deck avionics to access the required data. Analysis showed that all target and ownship

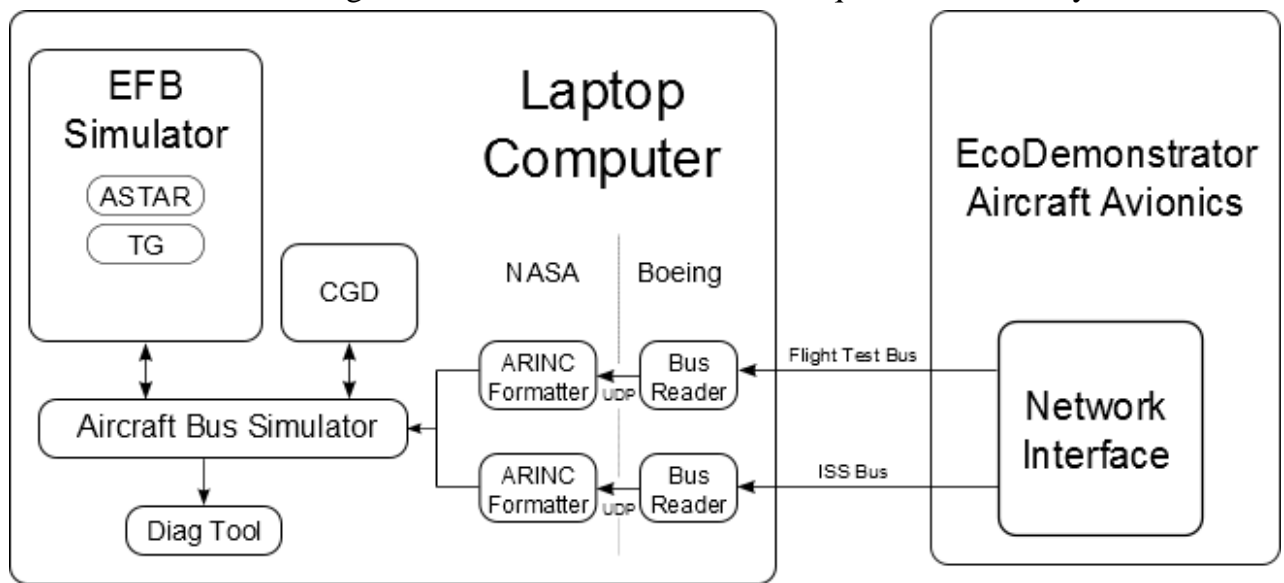

Figure 1. ATD-1 Phase 1 ecoDemonstrator Flight Demonstration Concept Diagram.

data necessary to support the ASTAR application could be made available on two accessible busses, the Integrated Surveillance System (ISS) Bus and the Flight Test Bus. Therefore, a laptop computer with two Ethernet interface ports was deemed necessary for the ASTAR Flight Test.

While the physical layer of the communication link between the flight test laptop computer and the ecoDemonstrator avionics was open, the network protocol and data format was proprietary. Therefore, Boeing developed a bus reader to serve as a gateway from the proprietary interface to the User Datagram Protocol (UDP). NASA then developed a module to read the UDP packets and convert the data into ARINC-429 words for placement onto the aircraft bus simulator. A diagnostic tool was also created to view real-time aircraft state data. This allowed the research engineer a quick look to ensure the state data were properly placed and correctly interpreted by the ASTAR algorithm.

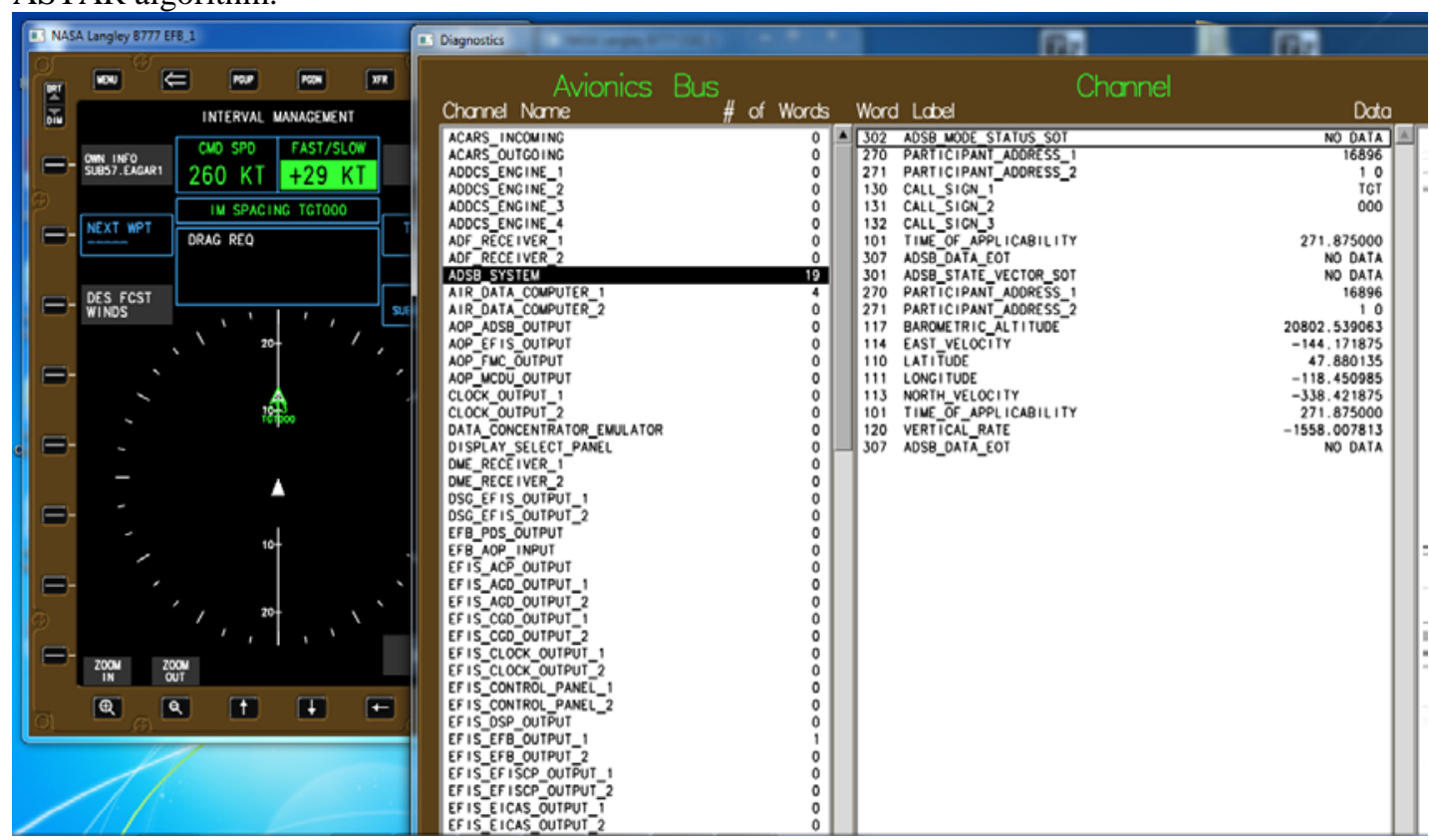

\section{Figure 2. Flight Research Diagnostic Tool.}

Existing technology to be used consisted of an Electronic Flight Bag (EFB) emulation and Configurable Graphics Display (CGD) previously developed at NASA Langley for Interval Management testing ${ }^{8}$. Speed outputs 
generated by the simulated aircraft bus were displayed on the EFB and CGD. Modifications to the ecoDemonstrator also improved ADS-B receiver sensitivity to allow reception from a farther range.

Lastly, to provide greater situational awareness to the researcher, a Flight Test Gateway window was created. It

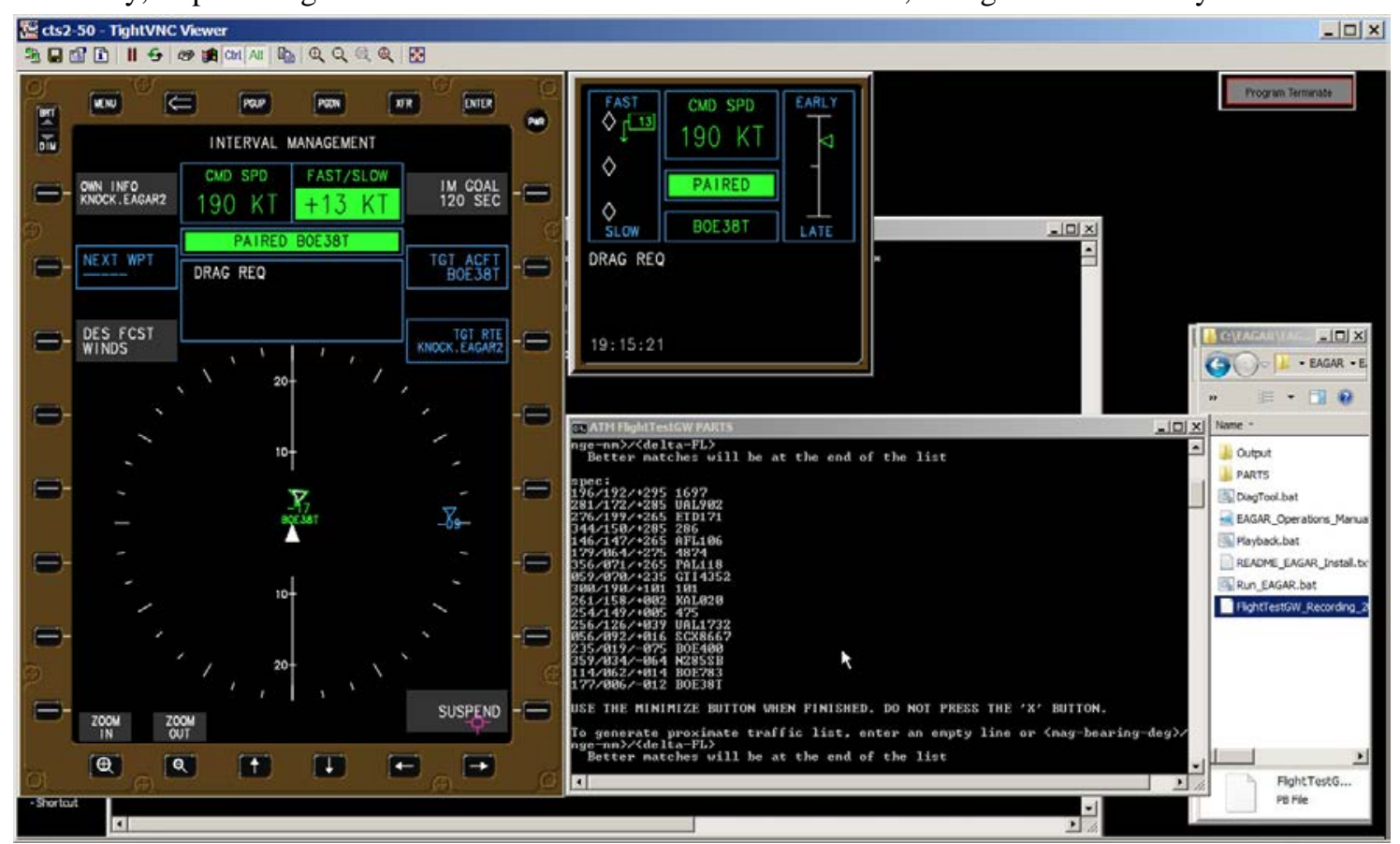

Figure 3. Flight Test Gateway Window.

displayed a list of all ADS-B In data currently received; showing magnetic bearing (deg), range (nmi), relative altitude (in hundreds of feet), and callsign.

\section{B. Simulation Testing}

Testing required two workstation-based simulations known as Aircraft Simulations for Traffic Operations Research (ASTOR) and a laptop for the operator' .

Two ASTOR aircraft driven by aerodynamic and engine models representative of a large 250,000-lb twinengine commercial transport category aircraft served as the ecoDemonstrator B787 and T-38 target. Included components for each ASTOR are: a six degrees of freedom aircraft model, Primary Flight Display, Multi-Function Display, autopilot and auto-throttle systems, Flight Management Computer, Multi-function Control Display Unit, Mode Control Panel, and ADS-B. Flight profiles were derived to determine speed and altitude constraints which would allow the T-38 target aircraft to mimic a

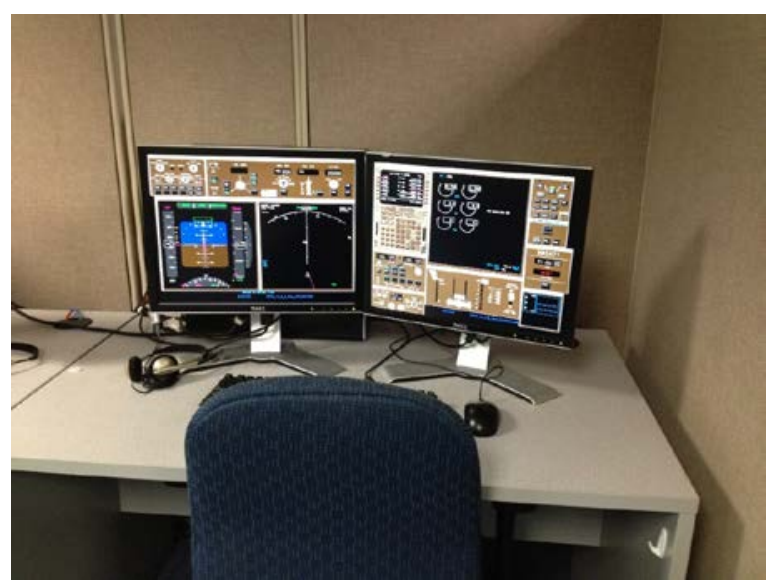

Figure 4. ASTOR Station standard transport category aircraft. The T-38 ASTOR station was configured using the developed flight profiles, then isolated in a separate room so the pilot would be unaware of activity in the other 'aircraft'. The other ASTOR station also had developed flight profiles inputted which allowed the simulation to determine a best guess optimized profile descent for a B787.

The laptop operator was seated near the B787 ASTOR station, but positioned such that speed command data were not visible to the pilot. A live intercom connected the two pilots and remained on mute, except during periods of communication between the two aircraft in order to simulate the actual demo.

Three separate scenarios were tested as planned for the flight test. The spacing goal for all scenarios was $120 \mathrm{~s}$ between both aircraft at the Final Approach Fix, providing a minimum $4.4 \mathrm{nmi}$ separation at the achieve-by point using typical approach speeds. The scenarios were tested in two configurations: one with the T-38 simulation on 
autopilot using the preconfigured altitude and speed restrictions developed; the second with the T-38 simulation under human control without the autopilot in order to test for nonconformity due to human variability.

In all conditions tested, the FIM ASTOR was able to arrive on time and maintain greater than $4 \mathrm{nmi}$ separation from the T-38 at the Final Approach Fix. These results suggested an acceptable level of separation for the planned flight demonstration aboard ecoDemonstrator.

\section{Boeing 787 Avionics Integration Lab Testing}

Aircraft and research systems checkout was conducted at Boeing Company facilities. A software interface was developed to retrieve ASTAR required data from Boeing proprietary B787 network buses. Bench testing occurred at the Boeing 787 Avionics Integration Lab.

The Boeing bench simulation unit allowed researchers to simulate multiple aircraft moving at predefined altitudes along specified trajectories. This was used to validate correct data flow from the ADS-B receiver to the flight test laptop. The bench testbed contained B787-800 specific hardware and software including the actual modified ISS to be used aboard the demonstration aircraft.

\section{Ground Testing}

A ground test onboard the B787 was conducted at Boeing Field (KBFI) to determine positive connectivity and functionality for the aircraft avionics-to-laptop setup. ADS-B functionality was confirmed with the T-38 nearby on the same airfield, as well as confirmation of expected alphanumeric identifier for the target aircraft. The algorithm could only be partially tested in static aircraft mode.

As selected target aircraft speed inputs surrounding Boeing field came through the ADS-B unit, the ground speed and ground track produced spikes in the data prior to ASTAR processing. A filter was implemented which excluded both velocities from updating on a given report if either showed unreasonable deviation. Because the algorithm could 'coast' for up to $30 \mathrm{~s}$, there was a reasonable amount of time for the velocities to update and pass the filter parameters.

Data from the actual flight demonstration still contained spikes, although frequency was significantly reduced.

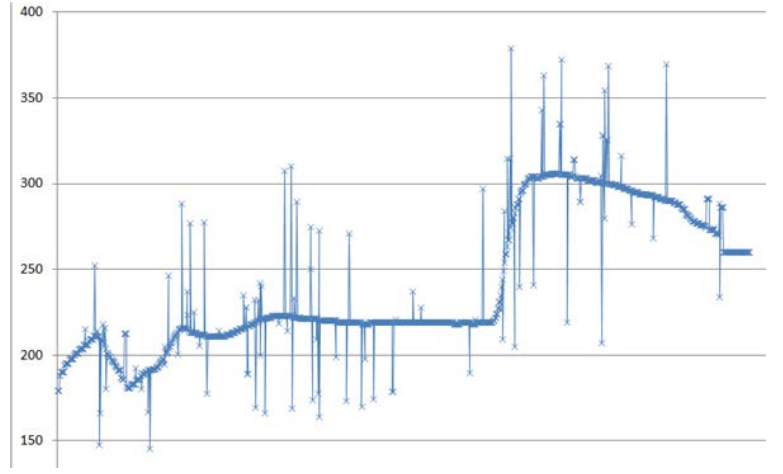

Figure 5. Ground speed pre-process data spikes.

\section{E. Air Traffic Control Coordination}

Through multiple meetings, NASA, Boeing, and members of the Seattle Center and Moses Lakes Approach developed procedures used during the flight demonstration. The B787 and T-38 were treated as a flight of two with the T-38 as the lead (or target) aircraft. Since the B787 was performing Interval Management, it was determined to also be the communications leader. Special handling was needed between Seattle Center and Grant County Approach, because although the test aircraft were a flight of two, during some portions of each test run both aircraft would fly separate instrument approaches. A flight plan was filed for every run of each aircraft resulting in a total of ten flight plans in the system.

\section{F. Flight Test Plan Development}

In order to increase the likelihood of obtaining visual conditions if adverse weather moved through the test area, two routes were created. Both routes were constructed roughly orthogonal to existing airways and jet routes in order to minimize potential traffic conflict and increase the likelihood of an uninterrupted run. The merge at HAMUR waypoint met that option by combining separate routes just prior to the airport instrument approach procedure.

The two available routes were the western SUBDY Arrival beginning at SUB42 and the eastern KNOCK Arrival beginning at KNOCK. Multiple routes allowed the two aircraft to be pre-positioned based upon local traffic loads to maximize the chances for an uninterrupted demonstration run, while allowing both vehicles to see and avoid other aircraft and increased the likelihood of avoiding adverse weather. 


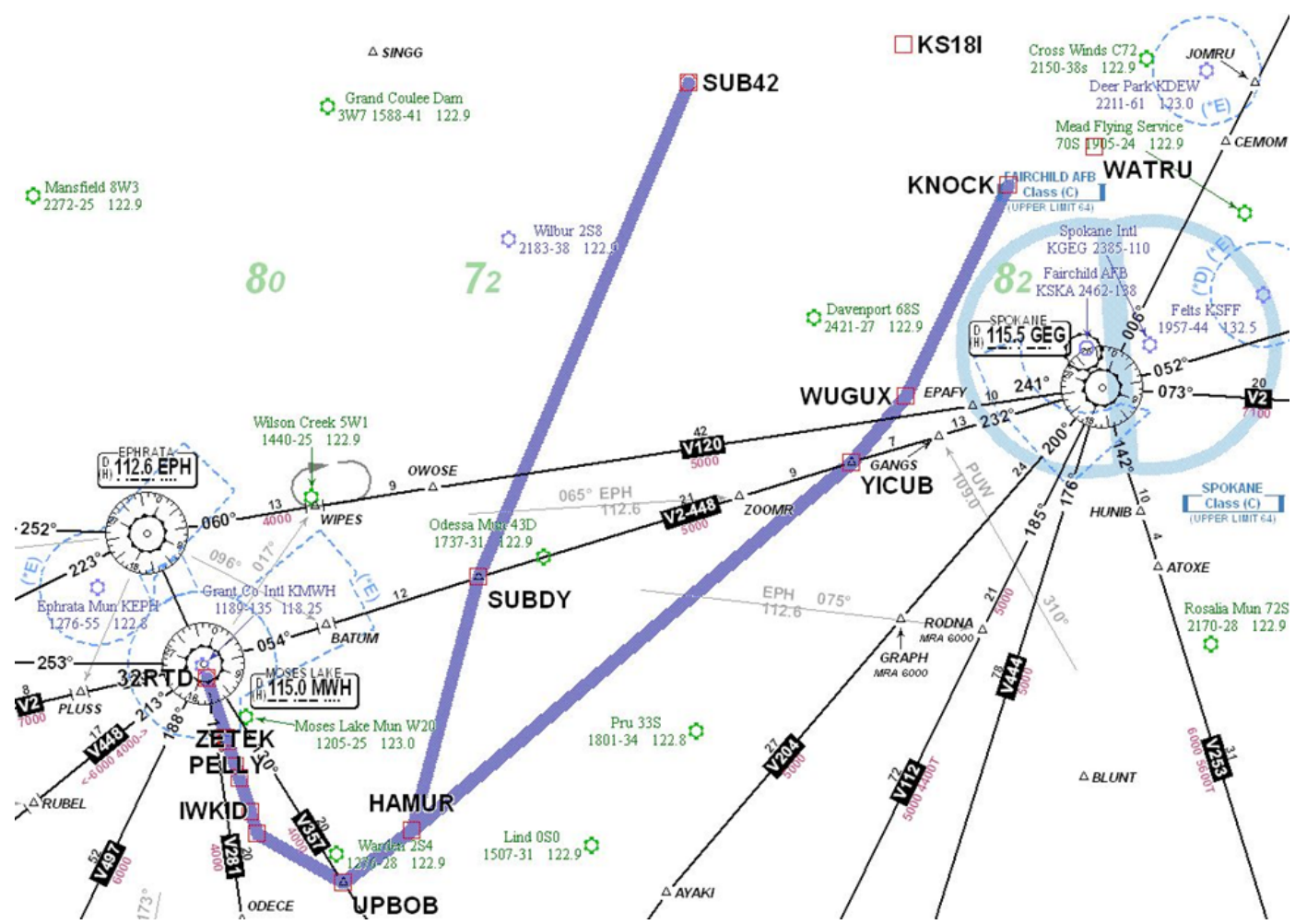

Figure 6. Final Test Routes for the ASTAR Flight Test.

Three scenarios were used with the B787 ownship following the targeted T-38. In the first scenario, both aircraft flew the SUBDY Arrival. In the second scenario, both aircraft flew the KNOCK Arrival. For the third scenario, the T-38 would fly the SUBDY Arrival, whereas the B787 would fly the KNOCK Arrival, merging at HAMUR behind the T-38.

\section{G. Test Conditions}

Although flying the same route, different equipage caused the T-38 to fly the Instrument Landing System approach to Runway 32R, whereas the B787 instead flew the Area Navigation (RNAV) approach to the same runway. The final approach fix for the RNAV approach was the pre-determined FIM termination point and also a convenient recognition point for the test pilots to begin other non-IM-related testing. Also, due to the difference in route lengths in Scenario Three (Runs 4-5), the B787 had $7.5 \mathrm{nmi}$ further to travel to the FIM termination point and could be thought of as initially having $7.5 \mathrm{nmi}$ along-path separation from the T-38. Concurrent arrival at the Initial Approach Fix (IAF) allowed adequate spacing for Air Traffic Control (ATC) purposes.

Approximately two to five demonstration runs were expected during a single six-hour flight. Therefore, five runs were defined with priority given to Scenarios 1 and 2. To ensure sufficient separation, the aircraft were given initial flight conditions for each run of 120 s separation as the assigned spacing goal:

\begin{tabular}{|l|l|l|l|}
\hline Run 1 & FL220 & 280 KIAS & SUBDY Arrival, 13 nmi In-Trail distance \\
\hline Run 2 & FL220 & 280 KIAS & KNOCK Arrival, 16 nmi In-Trail distance \\
\hline Run 3 & FL220 & 280 KIAS & SUBDY Arrival, 10 nmi In-Trail distance \\
\hline Run 4 & FL220 & 280 KIAS & Arrive concurrently at IAFs ( 7.5 nmi ‘along route’ distance) \\
\hline Run 5 & FL220 & 280 KIAS & Arrive concurrently at IAFs ( 7.5 nmi ‘along route’ distance) \\
\hline
\end{tabular}

Table 1. Demonstration Initial Conditions Plan. 


\section{Flight Testing}

\section{A. Functional Flight Test}

Prior to the dedicated portion of the flight demonstration, a functional flight test was allotted to the ASTAR Flight Test which successfully tested the software package, transmission of data, and laptop readability. With the foreknowledge that Boeing would depart from and return to Boeing Field, the team developed routes into Seattle using the existing Standard Terminal Arrival Route structure already in place.

Testing fully verified the correctness of incoming data channels and laptop functionality.

The ecoDemonstrator pilot, with the help of Seattle Center, positioned the aircraft behind a commercial flight and successfully maintained a time-interval separation from the preceding aircraft using speed guidance given by the ASTAR algorithm.

\section{B. Demonstration Flight}

The demonstration began at Boeing

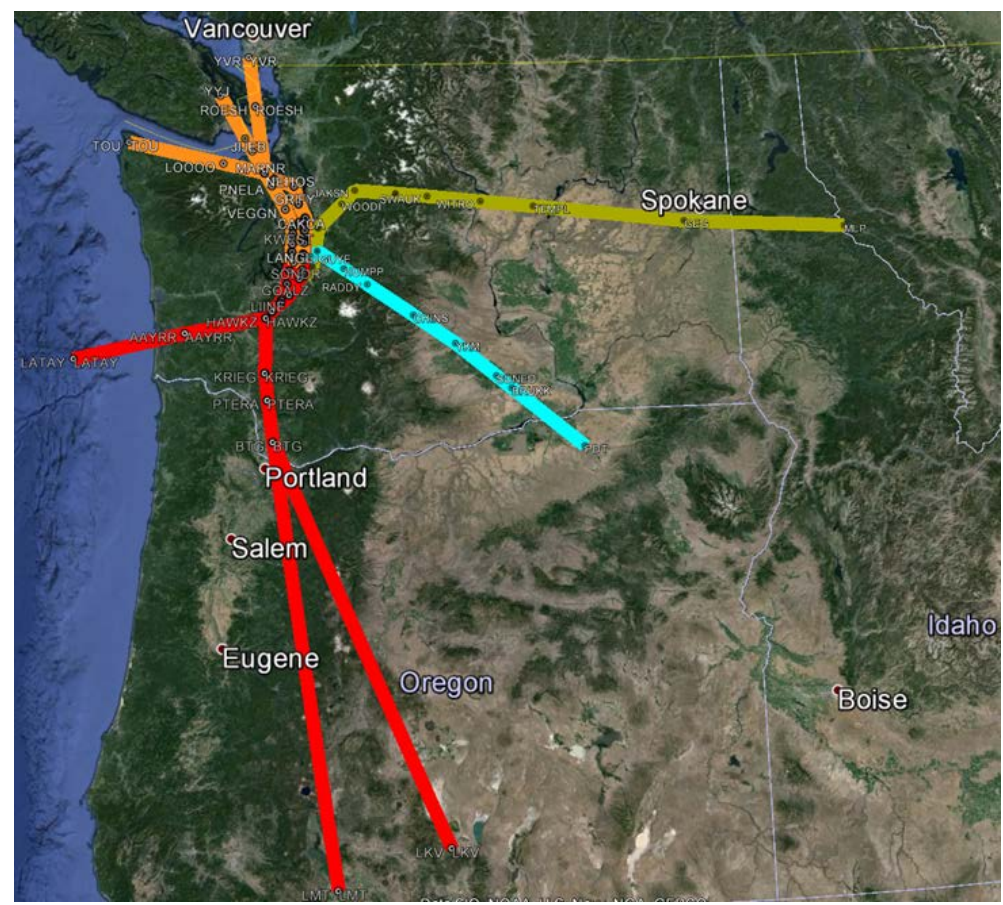

Figure 7. Developed Seattle routes for Functional Test Flight.

Field / King County International Airport on December 12, 2014. Both aircraft departed KBFI and climbed to cruise altitude heading toward Grant County International Airport. Once above 10,000 feet, the laptop operator turned on the Boeing provided demonstration laptop and set up for the demo. The laptop operator requested cruise speed, descent speed, forecast winds, and expected initial route from the cockpit to enter into the EFB. All operations occurred within the aircraft's normal flight envelope.

A moisture system along the West Coast created stratus cloud layers between 8,000 and 22,000 feet mean sea level within the test region. Cruise altitudes were adjusted to FL230 to the testing location, and for safety reasons, the T-38 performed a higher than normal descent rate until clear of any cloud layer.

\section{Results}

Feedback received from any pilots and controllers involved in the flight test have been complimentary of the spacing accuracy of the arriving test aircraft. A targeted goal was to demonstrate consistent final spacing within $\pm 5 \mathrm{~s}$ at the FIM termination point. When weighing all runs against the expected time of arrival, the ownship aircraft was on average $1.22 \mathrm{~s}$. early (-1.22 s.).

It should be noted that the test pilots had neither FIM training, nor the FIM expertise prior to the flight demostration. On the initial run, the B787 arrived $7.5 \mathrm{~s}$ early (112.5 s separation), almost twice the error for any other run and is equated to this lack of training. For the case study in Figures 9 to 11, the T-38 crossed SUB42 waypoint early, which caused the B787 to join at WUGUX waypoint, leaving a $1.63 \mathrm{nmi}$ 'along route' separation. ASTAR commanded a

\begin{tabular}{|c|c|}
\hline Run \# & Delivery Accuracy (sec) \\
\hline 1 & -7.5 \\
\hline 2 & 1.5 \\
\hline 3 & 1.4 \\
\hline 4 & 2 \\
\hline 5 & -3.5 \\
\hline Std. Dev. & 4.16 \\
\hline Range & 9.5 \\
\hline
\end{tabular}

Table 2. Interval Management Precision. 


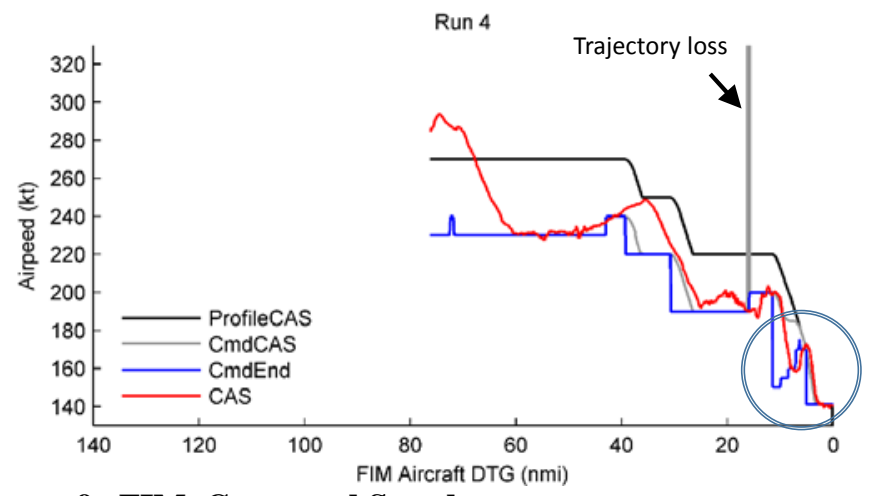

Figure 9. FIM Command Speeds.

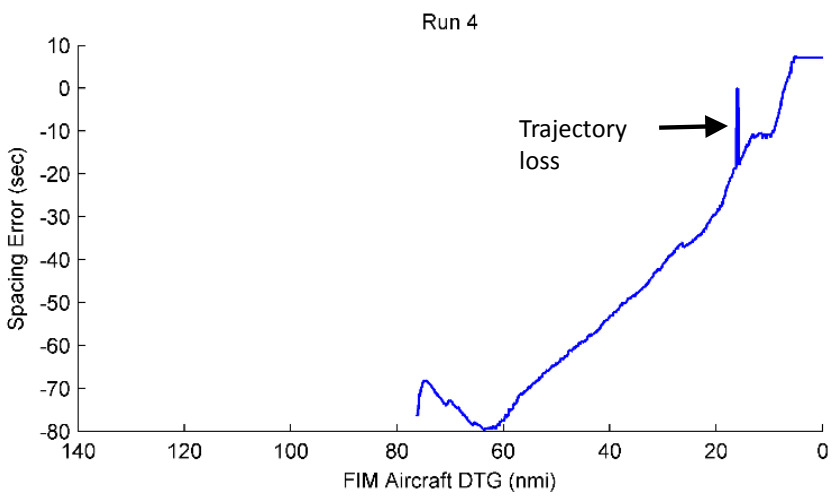

Figure 10. Spacing Error.

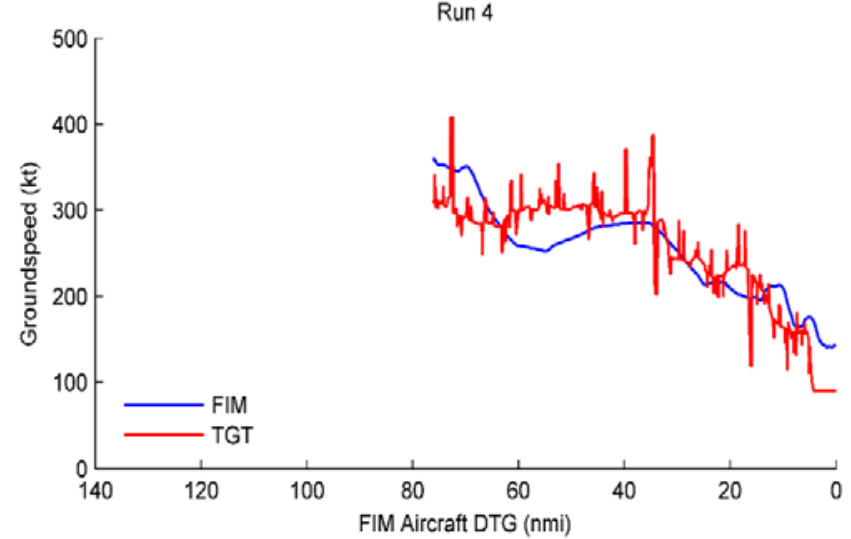

Figure 11. Aircraft Groundspeed. much lower speed of 230 knots rather than the 270 knot profile speed in order to reduce spacing error (Fig. 9), which in turn, increased separation distance between both aircraft. A lower than profile speed resulted in a steady progression to null the spacing error (Fig. 10).

Decelerations by the T-38 and design of the arrival led to large drops in Commanded FIM speeds. During the approach phase, increased airspeed by the T-38 to maintain level flight caused faster than expected groundspeeds resulting in a stepwise increase to the commanded end speed (Fig. 9, circle). Similar increases to commanded speeds occur due to excessive T-38 ground speeds at 72 and $43 \mathrm{nmi}$ (Fig. 11).

A $7 \mathrm{~s}$ loss of target trajectory data occurred approximately $16 \mathrm{nmi}$ prior to the airport, resulting in a noticeable loss of commanded speed within the EFB simulation on the research laptop. During the period of data loss, the target trajectory data displayed a 120 degree shift from the correct heading.

\section{Conclusion}

Results from the December 2014 flight test ;uggest operational use of a speed command for ;afe and manageable spacing operations is easible. Rapid prototyping using a low cost test zonfiguration aboard a test aircraft for Interval Management arrival operations was realized and will serve as the springboard for further levelopment efforts. Discovered risks from the ASTAR Flight Test revealed a need to focus on silot and controller specific training to ensure zorrect flight geometries and understanding of FIM procedure, as well as help envisioned industry IM training needs for NEXTGEN participants. Also, a diagnostic tool was essential to ensuring correct data streaming during the requirements definition phase. The outcome of this flight test facilitated a follow-on NASA effort to build, test, and fly a prototype IM system with industry partners which include The Boeing Company, Honeywell, and United Airlines for a multi-aircraft flight test in 2017.

\section{Acknowledgments}

The authors wish to thank the NASA software development team for their countless hours of hard work, Seattle and Grant County FAA Facilities for their support of the flight test, and especially The Boeing Company for funding and support, without which this opportunity might never have been possible. 


\section{References}

${ }^{1}$ Federal Aviation Administration, “NextGen Implementation Plan August 2014,” URL: http://www.faa.gov/nextgen/library/media/implementation/media/nextgen_implementation_plan_2012.pdf [cited 24 April 2015].

${ }^{2}$ K. A. Swieringa, M. C. Underwood, B. Barmore, R. D. Leonard, “An Evaluation of a Flight Deck Interval Management Algorithm including Delayed Target Trajectories” in $14^{\text {th }}$ AIAA Aviation Technology, Integration, and Operations Conference (ATIO), Atlanta, 2014.

${ }^{3}$ S. R. Wilson, J. L. Murdoch, C. E. Hubbs, K. A. Swieringa, “Evaluation of Flight Deck-Based Interval Management Crew Procedure Feasibility”, AIAA Modeling and Simulation Technologies (MST) Conference, Boston, 2013.

${ }^{4}$ S. R. Wilson, J. L. Kibler, C. E. Hubbs, J. A. Smail, (2015) Air Traffic Management Technology Demonstration - 1 Research and Procedural Testing of Routes. NASA Technical Memorandum 218707.

${ }^{5}$ T. J. Callantine, M. Kupfer, L. Martin, J. Mercer, T. Prevot, “System-Level Performance Evaluation of ATD-1 GroundBased Technologies”, 14 ${ }^{\text {th }}$ AIAA Aviation Technology, Integration, and Operations Conference (ATIO), Atlanta, 2014.

${ }^{6}$ Norris, G., “Advancing Eco,” Aviation Week and Space Technology, Vol. 174, No. 26, 23 Jul. 2012, p. 18.

7“Safety, Performance and Interoperability Requirements Document for Airborne Spacing-Flight Deck Interval Management (ASPA-FIM),” RTCA DO-328, RTCA, Washington, DC, (in press)

${ }^{8}$ B. T. Baxley, R. F. Shay, K. A. Swieringa (2014) The Development of Cockpit Display and Alerting Concepts for Interval Management (IM) in a Near-Term Environment. NASA Technical Memorandum 218659, pp. 51-53.

${ }^{9}$ D. Liu, W. W. Chung, “ASTOR: An Avionics Concept Test Bed in a Distributed Networked Synthetic Airspace Environment”, AIAA Modeling and Simulation Technologies Conference and Exhibit, Providence, 2014. 